\title{
New ideas and framework for combating COVID-19 pandemic using IoT technologies
}

\author{
Hussein M. Haglan', Akeel Sh. Mahmoud ${ }^{2}$, Mustafa Hamid AL-Jumaili ${ }^{3}$, Ahmed J. Aljaaf ${ }^{4}$ \\ ${ }_{1,2,4}$ Computer Center, University of Anbar, Iraq \\ ${ }^{3}$ Renewable Energy Research Center (RERC), University of Anbar, Iraq \\ ${ }^{4}$ Faculty of Enginnerig and Technoloy, Liverpool John Moores University, United Kingdom
}

\begin{tabular}{l}
\hline Article Info \\
\hline Article history: \\
Received Feb 26, 2021 \\
Revised Jun 7, 2021 \\
Accepted Jun 13, 2021 \\
\hline
\end{tabular}

\section{Keywords:}

Coronavirus

COVID-19

Internet of things

IoT techniques

Pandemic

\begin{abstract}
The internet of things (IoT) is one of the most advanced technologies that have emerged in the last decade. In recent years, IoT has been used in many medical fields. With the emergence of the Coronavirus pandemic, some IoT technologies were employed to serve the health sector to make quick and accurate decisions to save people's lives. However, there are still many ideas and works not yet implemented that could be applied in many aspects to preserve people's lives. Therefore, it is necessary to collect works and ideas that depend on IoT to produce modern systems quickly to serve the health sector. In this paper, a review of the most recent technologies of IoT against Coronavirus disease (COVID-19) has been done. A comparative and analysis among the previous works have been done to reach the most efficient depending on comparing the services that each work has provided. Besides that, suggest several new ideas that can be adopted as systems use IoT technologies and the expected advantages that can be gain from applying these ideas. A framework for a proposed idea to build a comprehensive monitoring system based on IoT technologies on the patient and hospital sides and expected advantages of implementing the system has been done.
\end{abstract}

This is an open access article under the CC BY-SA license.

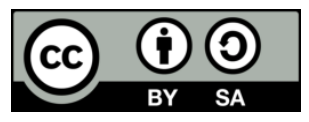

\section{Corresponding Author:}

Hussein M. Haglan

Computer Center

University of Anbar

Ramadi, Anbar, Iraq

Email: hussein.m.haglan@uoanbar.edu.iq

\section{INTRODUCTION}

Wireless networks have seen continuous development in recent decades such as MANETs [1]-[3],

Cellular mobile networks, intelligent systems [4], [5], and one of the important things that have been developed in recent years is the so-called internet of things (IoT) [6], [7]. The increase in tasks entrusted to humans and the pressure of work that causes a lack of precision and focus in accomplishing these tasks, one of the reasons that led to the emergence of the idea of the internet of things and became the best solution to many problems in human life [8]. Internet of things has been used in many areas of human life, such as education [9], industry [10], [11], agriculture [12], health [13], and smart home [14]. The main idea of the internet of things is the link between the physical parts such as cars, homes, planes, and the human body through devices that contain programs in anytime and anywhere in the world that helps human to control them remotely, or it is an alternative to the human being to make a faster and more accurate decision [15]. The internet of things has been used in many areas that have greatly assisted humans, and it has become one 
of the major revolutions in the field of developing wireless networks [16]. One of the important areas in which the internet of things has been applied in the healthcare sector to preserve human life [17].

The internet of things has been used in many areas of health care, such as monitoring the health of patients in hospitals, assisting doctors in making decisions, and relieving pressure on them during the practical effort [18]. As we all know, the world is now exposed to a dangerous virus attack, which is COVID-19, which is likely to kill any young or old person, strong or weak, rich or poor because it is a dangerous virus, blind, and can't be seen by the naked eye, except through symptoms that appear on a person [19]. With the massive spread of this virus in all countries of the world, it has become difficult for health personnel to follow and monitor all people to conduct tests to detect the virus or monitor the health status of all people infected with this virus because the number of infections has reached very large numbers, so it has become difficult to control them by health personnel only. Therefore, the researchers in the past few periods have developed some technologies that help to detect the virus, monitor the health status of patients infected with this virus, and make some decisions on behalf of health personnel automatically.

This research greatly contributes to supporting the health sector to save the lives of people infected with Coronavirus disease (COVID-19) by helping researchers to: Quickly access the most efficient systems that use the internet of things technologies that have been adopted to combat the Corona pandemic in order to develop more efficient systems. Ideas that have been proposed in this research, methods of implementing them, and the expected advantages of each idea in order to help researchers. A framework for building a comprehensive and intelligent emergency system between patients moving inside or outside homes and hospitals and the expected benefits of implementing this system.

This research is organized as follows: The second section is related work. The third section is systems that can rely on IoT techniques to face the COVID-19 pandemic. The fourth section is the framework for a proposed idea. The fifth section is the expected advantages of implementing the system. The last section is the conclusion.

\section{RELATED WORK}

In recent decades, many researchers have developed and improved many ideas and research in the field of the internet of things in many fields to serve the human community [20]-[21]. In the industry, for example, wireless monitoring and control of many factories [22]. In agriculture, irrigation levels are controlled depending on weather conditions [23]. Education, for example, attendance systems and recording the absence of students [24]. Health, for example, systems to monitor the health of hospitalized people [25].

Today, in light of the recent circumstances the world witnessed with the spread of the COVID-19 virus, the world was completely paralyzed in all aspects of life. The first line of defense against COVID-19 is the medical staff in the health sector to counter this deadly virus. With all the human capabilities and equipment, it has become difficult for medical staff to monitor the large number of people who have been infected with this virus, and to provide tests for people to detect this virus, as well as to give appropriate care to all cases that have been confirmed with the virus. Therefore, the researchers worked on developing some systems that adopt internet of things technologies to help medical staff in detecting people with this virus and also provide appropriate care for those infected with speed and the right time to save the lives of people. Some examples of the IoT techniques systems are system of patiant's temperature monitoring, system of patiant's oxygen body measurement, heart rate measurement system, and other systems that work to control the level of oxygen given to the patient according to his health condition, and so on.

In the last months, there are some new related works that depend on IoT techniques to build systems that have been helped the health sector stand against Covied-19. The most important of these related researches have been browsed in Table 1 (see appendix). Table 2 (see appendix) shows a comparison between the services provided by the most important previous works that adopt IoT technologies to combat COVID-19. Despite some of these previous works like the last one was the most diversified in providing services to help limit the outbreak of the COVID-19 compare to other works, but there is still a great need to activate new ideas which can exploit IoT technologies to stand against the Corona pandemic on a larger scale. Especially with the tremendous pressure on the health sector because of the great outbreak of this virus around the world.

\section{IOT SYSTEMS FACING COVID-19 PANDEMIC}

In this section, an important idea that can rely on IoT technologies as a platform in their works have been suggested which can help researchers to build and develop systems to stand against the Coronavirus, as shown in Figure 1. The suggested method that researchers can follow to implement each idea as a system and the expected advantages of implementation of this idea are reviewed in Table 3. 


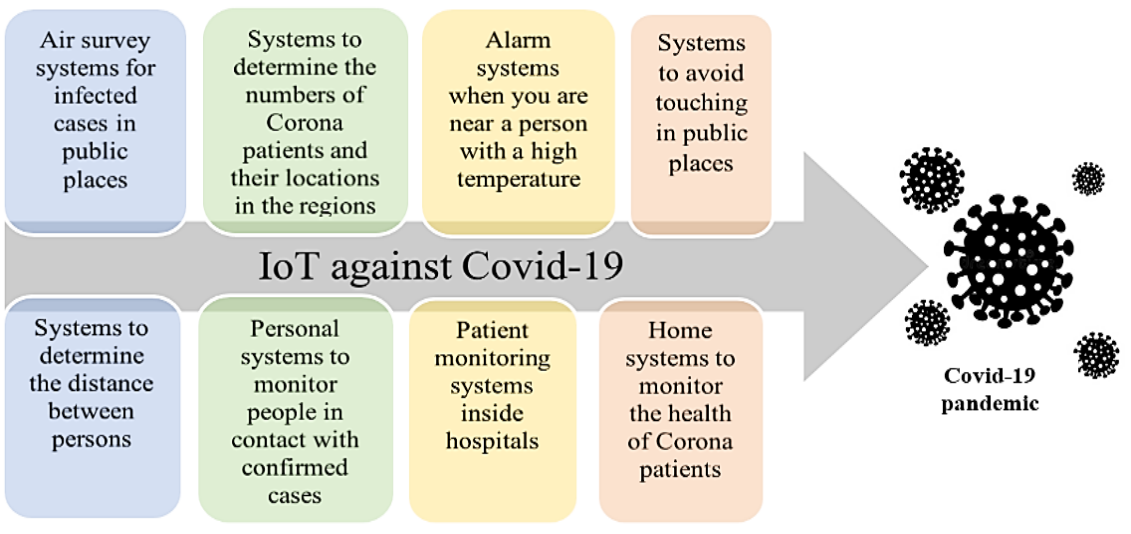

Figure 1. Many of the ideas can apply as systems against the COVID-19 pandemic depending on IoT techniques

Table 3. The method and advantages of each proposed system based on IoT techniques

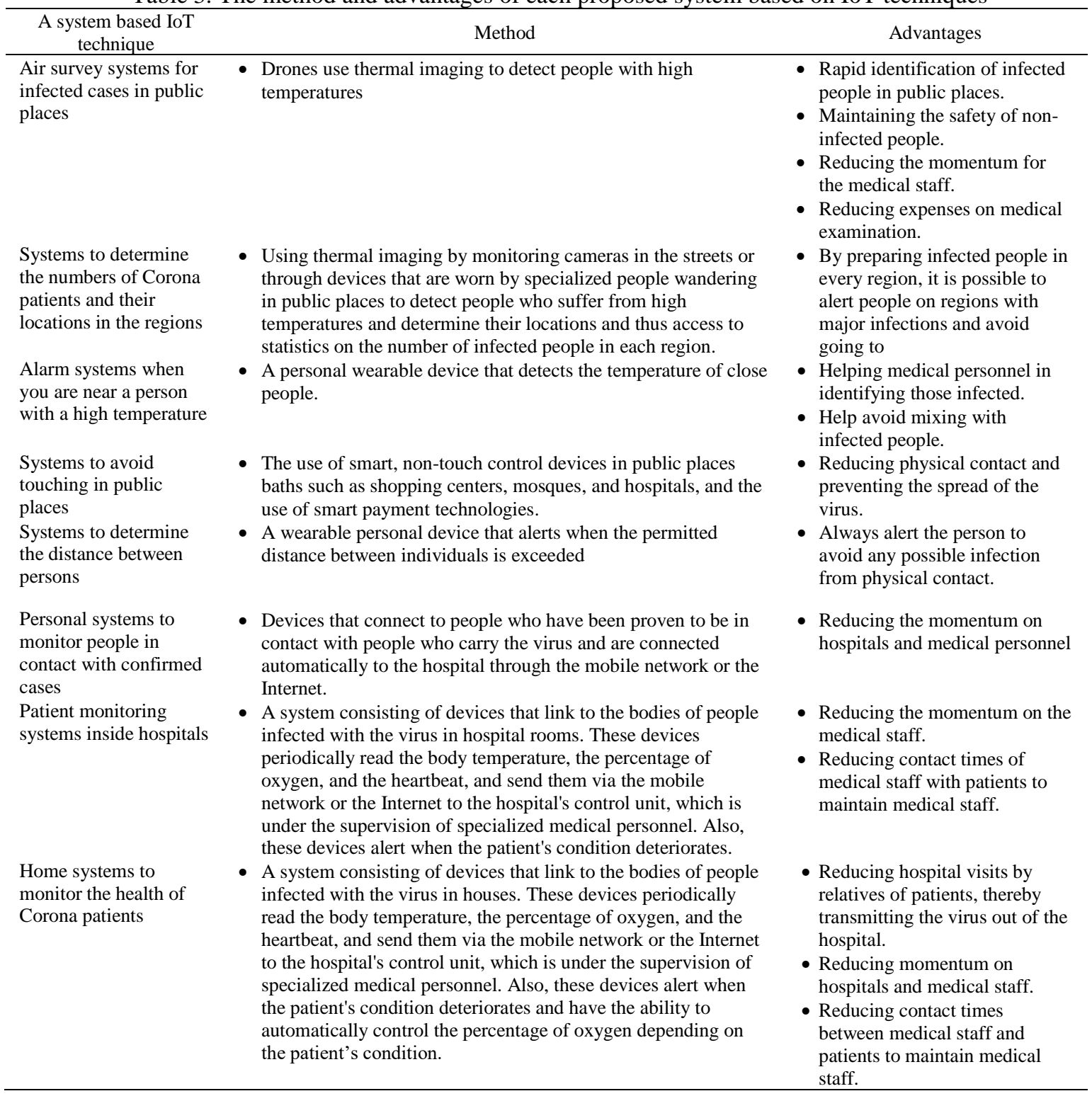




\section{FRAMEWORK FOR A PROPOSED IDEA}

The internet of things (IoT)is an innovative platform to build a system against the COVID-19. Among the most important steps that can be taken to build an integrated system against Coronavirus are: i) First step: Using a variety of internet of things technologies, health data about infected patients is collected from several sites through continuous monitoring; ii) Second step: Building a virtual management system that analyzes the collected data and makes the appropriate decisions based on the experience gained from the analysis of the previous data; iii) Third step: Analyze new data and make immediate quick decisions to aid critical cases of patients with COVID-19; iv) Fourth step: Controlling the data and following up the incoming and outgoing reports of the patients infected with Coronavirus.

The idea of the system in the form of steps that can be relied upon to support the health sector has shown in Figure 2. Figure 3 shows a framework for one of the proposed ideas that can be constructed using IoT technologies. The idea is to build an integrated system to monitor mobile people infected with Coronavirus, inside or outside homes. This system consists of three main parts: The first part is called the Transmitter part of the proposed system with mobile patients (TPSMPs), where each patient has its TPSMP. The second part is called the receiver part of the proposed system in hospitals (RPSHs), where each hospital has its RPSH. The third section is an intelligent emergency system in the main controller unit.

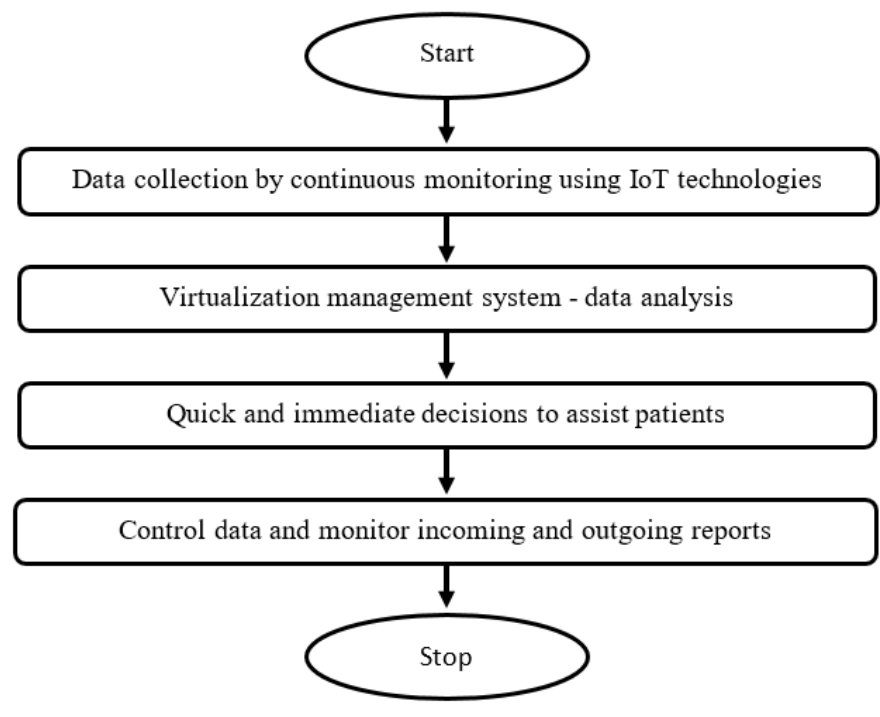

Figure 2. Implementations steps of the proposed system that uses IoT techniques

The TPSMP consists of several sensors to measure the temperature of the patient's body, heart rate, oxygen percentage, blood pressure, blood sugar, and locate the patient's location. The values received from these sensors are transferred to a control unit that collects this information in the form of a message called message of mobile patient (MoMP) and this message is sent through the global system for mobile communications (GSM) network to the RPSH in hospitals. The RPSH consists of a receiving system that receives the incoming MoMP messages from TPSMPs through the GSM network and displays them on monitoring screens to be viewed by the specialists. Copies of the MoMP messages are sent to the intelligent emergency system.

The main controller unit consisting of an intelligent emergency system on a server. The intelligent emergency system analyzes the data contained in the MoMP messages and takes appropriate decisions in emergency cases. If the data in the message indicates that the patient's condition is normal, the system will only display that message on the screens in hospitals for monitoring by specialist doctors. But, if the received message contains data indicating to find a critical case, the system works to alert the specialist doctors by sending an emergency message to the nearest hospital to the patient's location, including the patient's condition data, to present it to the specialist doctor and send the ambulance to the patient's location as soon as possible. Besides, an emergency message containing some first aid instructions called (EMFA) is sent to one of the patient's relatives until the ambulance arrives. 


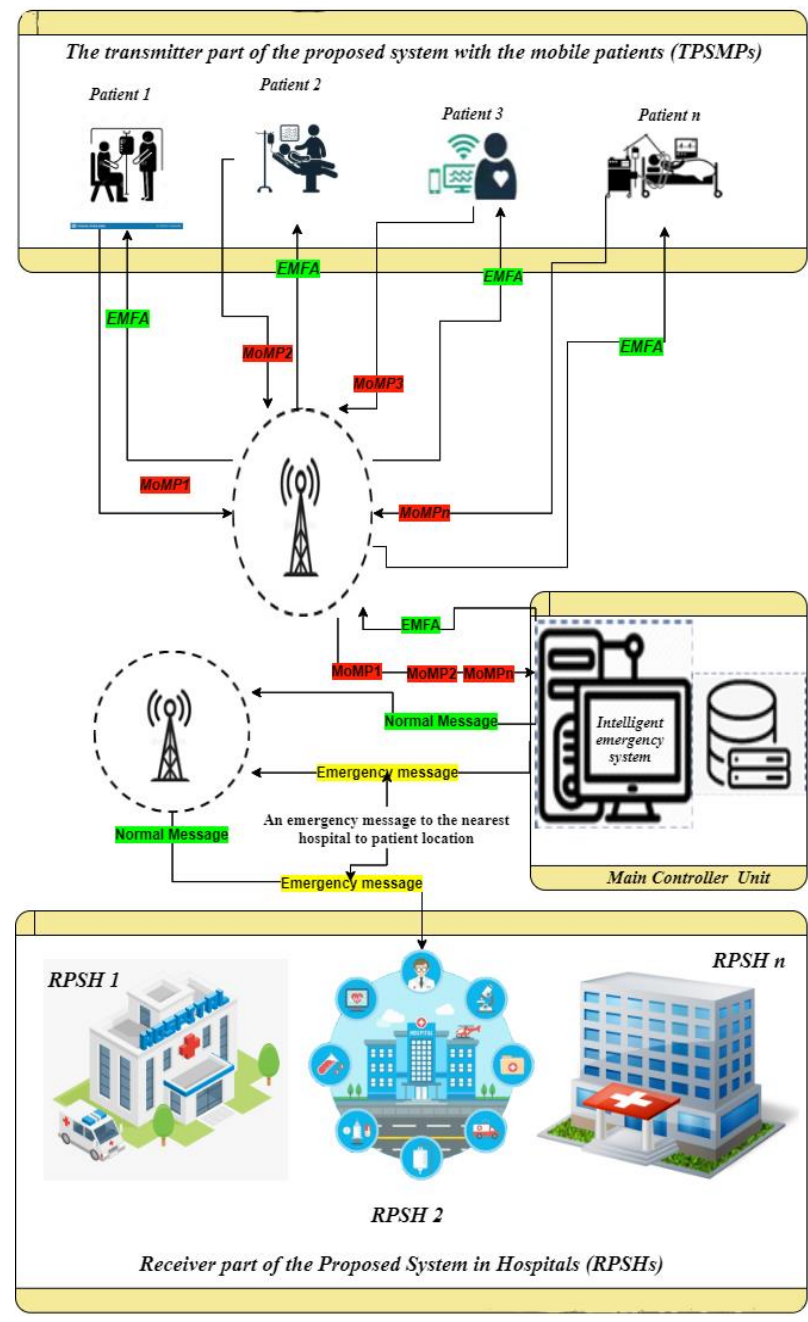

Figure 3. Framework for a proposed idea

\section{THE EXPECTED ADVANTAGES}

The important advantages that can be obtained when implementing a comprehensive monitoring system based on the internet of things technologies on the patient and hospital sides to stand against the Corona pandemic can be summarized as follows: i) To capture real-time data and other necessary information about the condition of a patient with Coronavirus [38]-[40]; ii) Ensure that all people infected with the virus are quarantined; iii) A system based on IoT technologies is considered as a rapid and immediate monitoring system; iv) Track all patients at risk of this virus through the Internet, by monitoring blood pressure, temperature, heart rate, and oxygen levels [41]; v) Improve the efficiency of the medical staff; vi) Relieve pressure and burden on medical personnel; vii) Reducing the percentage of errors that may occur as a result of work pressure.

\section{CONCLUSION}

In this paper, the importance of IoT technologies in building smart systems is explained and how they are used to support the health sector. In the related work section, special emphasis has been placed on the latest previous researches that have adopted various technologies from the internet of things to stand against the COVID-19 pandemic, by reviewing and analyzing the method, goals, and results of each research. Some of the most important works were reached by comparing and analyzing these works with each other depending on the services that each system can provide. Also, many ideas that can be adopted as systems based on IoT technologies that can support the health sector to combat the Coronavirus were proposed. A framework was proposed for one of the ideas that could be adopted as a comprehensive monitoring system between patients moving in and out of homes and hospitals using an intelligent emergency system. Some of the expected benefits that could be gained from implementing the proposed framework were presented. 


\section{APPENDIX}

Table 1. The most important previous works that used IoT techniques against COVID-19 pandemic

\begin{tabular}{lll}
\hline \multicolumn{1}{c}{ Reference } & \multicolumn{1}{c}{$\begin{array}{c}\text { The IoT } \\
\text { techniques }\end{array}$} & \multicolumn{1}{c}{ The method of } \\
\hline $\begin{array}{l}\text { Swayamsiddha } \\
\text { \& Mohanty in }\end{array} 2020$ [26] & CIoMT & $\begin{array}{l}\text { Connect all persons to } \\
\text { monitor and manage } \\
\text { cases of COVID-19. }\end{array}$ \\
Nilashi et al. in & $\begin{array}{l}\text { The wearable } \\
\text { devices that } \\
\text { depend on IoT }\end{array}$ & $\begin{array}{l}\text { Educating people on } \\
\text { the internet of things } \\
\text { wearable devices. }\end{array}$
\end{tabular}

Rahman et al. in 2020 [28]

Intelligent disease surveillance systems adopt IoT

Governmental directives to adopt rapid health measures based on smart technologies

Tripathy et al. in Easy Band adopt Automatic call tracking 2020 [29] IoMT Singh et al. in
$2020[30]$

Healthcare systems that rely on internet of things technologies

Fatima et al. in IoTSMCFIS 2020 [31]

Mohammed et al. in 2020 [32]

The Smart Helmet System

Wang et al. in SIoT 2020 [33]

Vasantharao \& Arduino UNO Arifunneesa in 2020 [34]

Mohammed et al. in 2020 [35]

Drones depending on the IoT

Ben Hassen $e$ al. in 2020 [36]

Use the IoT technique to build a home hospitalization system
Search using popular engines like Google Scholar, Scopes, and Research Gate about the keywords "COVID-19", "internet of things", and "IoT"

An IoT system was developed by sensors that connect to the patient's body, which connects to the database of the internal system that uses fuzzy logic technology to monitor patients and predict results to determine if the patient is infected with COVID-19 or not.

A smart helmet that contains a system that can automatically detect a virus IoT through complex thermal imaging

The social relationships between mobile devices (SIOT) were used to collect data related to the problem of the spread of COVID19 , after that, an RAI algorithm was proposed to solve this problem after converting this problem to the MWVC problem.

Smart tunnel designed using Arduino Uno technology and connected to the Internet to be placed in the entrances of markets and other crowded places

A system is designed that adopts the technology of the internet of things in the form of drones with the ability to use virtual reality for direct scanning on people to reveal the thermal image of people.

The most modern technologies

which are cloud computing, the internet of things, and fog computing, were used to build a home hospital system.
Objective

The result

Reducing time and effort on health personnel and accurate diagnosis to save people.

Check the advantages of devices that use the IoT technology and their benefits in case of outbreaks of diseases such as COVID-19, and educate people about wearing them.

Collecting and analyzing information obtained from smart monitoring systems that use IoT technologies

To reduce the cases that can be infected with COVID-19 and encourage the necessary social spacing

Explore and review most of the researches that use the internet of thing technologies to invest them in standing up against COVID-19.

To monitor patients and determine whether they are infected with COVID-19 or not.

Real-time tracking, ontact tracking, remote health monitoring, surveillance, rapid diagnosis of the cases, clustering, and screening. Finding the ability to use social media and advise agents on how to advertise and marketing to urge people the wearing devices that use the internet of things Help medical staff to the early identification of potential places to outbreaks of diseases to reduce the spread of COVID-19

The results expect that Easy Band in the future will be an integral part of smart healthcare components

Implementing IoTs technologies, reducing healthcare costs for Corona patients, and improving treatment outcomes

The outcomes of the proposed system were very satisfactory

Protecting health personnel from directly tach with COVID-19 patients

Helping to control the infection rate of Coronavirus through early diagnosis of infected cases.

To sterilize and measure the temperature of people entering to detect people with COVID-19

To detect the temperature of people on drones, using the internet of things technology.

To provide timely and appropriate health care to patients with COVID-19 and to reduce the momentum on hospitals and medical staff.
The outcomes of the proposed system were very satisfactory

The results showed that the proposed system could significantly reduce the prevalence of the Crohn virus

The system was tried and worked well and was satisfactory

The results were very beneficial and effective in the health sector.

The results of the system evaluation were satisfactory for the medical staff and patients. 
Table 2. A comparative between services that previous IoT systems contained to combat COVID-19

\begin{tabular}{|c|c|c|c|c|c|c|c|c|c|}
\hline Reference & 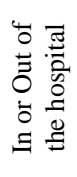 & 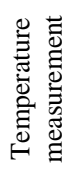 & 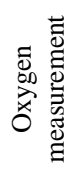 & 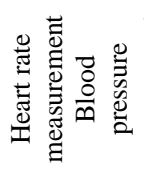 & 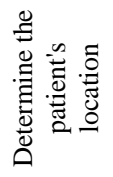 & 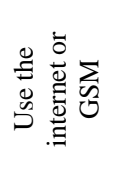 & 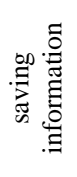 & 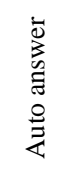 & 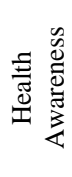 \\
\hline Nilashi et al. [27] & Out & & & & & Yes & & & \\
\hline Tripathy et al. [29] & Out & & & & & Yes & & & Yes \\
\hline Singh et al. [30] & Out & & & & Yes & Yes & & & \\
\hline Fatima et al. [31] & In & Yes & & & & & Yes & Yes & \\
\hline Mohammed et al. [32] & Out & Yes & & & Yes & Yes & & & \\
\hline Wang et al. [33] & Out & & & & Yes & Yes & & & \\
\hline Vasantharao \& Arifunneesa [34] & Out & Yes & & & & & & & \\
\hline Mohammed et al. [35] & Out & Yes & & & Yes & & & & \\
\hline Hassen et al. [36] & Out & Yes & Yes & Yes & & & & & \\
\hline Garg et al. [37] & Out & & & & Yes & Yes & Yes & Yes & \\
\hline
\end{tabular}

\section{REFERENCES}

[1] H. M. Haglan, S. Yussof, K. W. Al-Ani, H. S. Jassim, and D. A. Jasm, "The effect of network size and density to the choice of zone radius in ZRP," Indones. J. Electr. Eng. Comput. Sci., vol. 20, no. 1, pp. 206-213, 2020, doi: 10.11591/ijeecs.v20.i1.pp206-213.

[2] H. M. Haglan et al., "Analyzing the impact of the number of nodes on the performance of the routing protocols in MANET environment," Bull. Electr. Eng. Informatics, vol. 10, no. 1, pp. 434-440, 2021, doi: 10.11591/eei.v10i1.2516.

[3] K. W. Al-Ani, S. Yussof, H. M. Haglan, H. Shaker, and L. M. Alani, "Determining an optimum zone radius for zone routing protocol (ZRP) based on node mobility," Indones. J. Electr. Eng. Comput. Sci. (IJEECS), vol. 21, no. 2, pp. 1230-1237, 2021, doi: 10.11591/ijeecs.v21.i2.pp1230-1237.

[4] A. Bassel, H. M. Haglan, and A. S. Mahmoud, "Local search algorithms based on benchmark test functions problem," IAES Int. J. Artif. Intell., vol. 9, no. 3, pp. 529-534, 2020, doi: 10.11591/ijai.v9.i3.pp529-534.

[5] H. M. Haglan and A. S. Mahmoud, "The Data Mining Reliability for Melanoma Disease Diagnosis," J. Eng. Appl. Sci., vol. 13, no. 20, pp. 8591-8597, 2018, dx.doi.org/10.36478/jeasci.2018.8591.8597.

[6] H. M. Haglan and H. J. Ali, "An automatic system for detecting voltage leaks in houses tosave people's lives," Indones. J. Electr. Eng. Comput. Sci. (IJEECS), vol. 21, no. 3, pp. 1485-1492, 2021, doi: 10.11591/ijeecs.v21.i3.pp1485-1492.

[7] F. Xia, L. T. Yang, L. Wang, and A. Vinel, "Internet of Things," Int. J. Commun. Syst., vol. 25, no. 9, pp. 1101-1102, 2012, doi: 10.1002/dac.

[8] M. A. A. Majeed and T. D. Rupasinghe, "Internet of things (IoT) embedded future supply chains for industry 4.0: An assessment from an ERP-based fashion apparel and industry," Int. J. Supply Chain Manag., vol. 6, no. 1, pp. 25-40, 2017.

[9] A. S. Mishra, J. Karthikeyan, B. Barman, and R. P. Veettil, "Review on IoT in enhancing efficiency among higher education institutions," J. Crit. Rev., vol. 7, no. 1, pp. 567-570, 2020, doi: 10.31838/jcr.07.01.109.

[10] M. Bagheri and S. H. Movahed, "The Effect of the Internet of Things (IoT) on Education Business Model," in Proceedings - 12th International Conference on Signal Image Technology and Internet-Based Systems, SITIS, 2016, pp. 435-441, doi: 10.1109/SITIS.2016.74.

[11] M. H. Al-Jumaili, H. M. Haglan, M. K. Mohammed, and Q. H. Eesee, "An automatic multi-axis solar tracking system in Ramadi city: Design and implementation," Indones. J. Electr. Eng. Comput. Sci. (IJEECS), vol. 19, no. 3, pp. 1226-1234, 2020, doi: 10.11591/ijeecs.v19.i3.pp1126-1234.

[12] Aqeel-Ur-Rehman, A. Z. Abbasi, N. Islam, and Z. A. Shaikh, "A review of wireless sensors and networks' applications in agriculture," Comput. Stand. Interfaces, vol. 36, no. 2, pp. 263-270, 2014, doi: 10.1016/j.csi.2011.03.004.

[13] V. Subramaniyaswamy et al., "An ontology-driven personalized food recommendation in IoT-based healthcare system," J. Supercomput., vol. 75, no. 6, pp. 3184-3216, 2019, doi: 10.1007/s11227-018-2331-8.

[14] K. Yoshigoe, W. Dai, M. Abramson, and A. Jacobs, "Overcoming invasion of privacy in smart home environment with synthetic packet injection," in IEEE 2015 TRON Symposium (TRONSHOW), 2015, pp. 1-7, doi.org/10.1109/TRONSHOW.2014.7396875.

[15] P. P. Ray, “A survey on Internet of Things architectures," J. King Saud Univ. - Comput. Inf. Sci., vol. 30, no. 3, pp. 291-319, 2018, doi: 10.1016/j.jksuci.2016.10.003.

[16] M. Al-Jumaili and B. Karimi, "Maximum bottleneck energy routing (MBER) - An energy efficient routing method for wireless sensor networks," in IEEE Conference on Wireless Sensors, ICWiSE 2016, 2016, pp. 38-44, doi: 10.1109/ICWISE.2016.8187759.

[17] M. Usak, M. Kubiatko, M. S. Shabbir, O. V. Dudnik, K. Jermsittiparsert, and L. Rajabion, "Health care service delivery based on the Internet of things: A systematic and comprehensive study," Int. J. Commun. Syst., vol. 33, no. 2, pp. 1-17, 2020, doi: 10.1002/dac.4179.

[18] A. Darwish, A. E. Hassanien, M. Elhoseny, A. K. Sangaiah, and K. Muhammad, "The impact of the hybrid platform of internet of things and cloud computing on healthcare systems: opportunities, challenges, and open problems," J. Ambient Intell. Humaniz. Comput., vol. 10, no. 10, pp. 4151-4166, 2019, doi: 10.1007/s12652-017-0659-1. 
[19] F. Zhou et al., "Clinical course and risk factors for mortality of adult inpatients with COVID-19 in Wuhan, China: a retrospective cohort study," Lancet, vol. 395, no. 10229, pp. 1054-1062, 2020, doi: 10.1016/S0140-6736(20)30566-3.

[20] Y. Perwej, M. Ahmed, B. Kerim, and H. Ali, "An Extended Review on Internet of Things (IoT) and its Promising Applications," Commun. Appl. Electron., vol. 7, no. 26, pp. 8-22, 2019, doi: 10.5120/cae2019652812.

[21] K. Mekki, E. Bajic, F. Chaxel, and F. Meyer, "A comparative study of LPWAN technologies for large-scale IoT deployment," ICT Express, vol. 5, no. 1, pp. 1-7, 2019, doi: 10.1016/j.icte.2017.12.005.

[22] H. Nguyen et al., "Industrial Internet of Things, Big Data, and Artificial Intelligence in the Smart Factory: a survey and perspective," in ISSAT International Conference on Data Science in Business, Finance and Industry, pp. 72-76, 2019.

[23] A. A. R. Madushanki, M. N. Halgamuge, W. A. H. S. Wirasagoda, and A. Syed, "Adoption of the Internet of Things (IoT) in agriculture and smart farming towards urban greening: A review," Int. J. Adv. Comput. Sci. Appl., vol. 10, no. 4, pp. 11-28, 2019, doi: 10.14569/ijacsa.2019.0100402.

[24] A. Abuarqoub et al., "A survey on internet of things enabled smart campus applications," in ACM International Conference Proceeding Series, pp. 1-7, 2017, doi: 10.1145/3102304.3109810.

[25] H. Ahmadi, G. Arji, L. Shahmoradi, R. Safdari, M. Nilashi, and M. Alizadeh, "The application of internet of things in healthcare: a systematic literature review and classification," Univ. Access Inf. Soc., vol. 18, no. 4. Springer Berlin Heidelberg, 2019, doi.org/10.1007/s10209-018-0618-4.

[26] S. Swayamsiddha and C. Mohanty, "Application of cognitive Internet of Medical Things for COVID-19 pandemic," Diabetes Metab. Syndr. Clin. Res. Rev., vol. 14, no. 5, pp. 911-915, 2020, doi: 10.1016/j.dsx.2020.06.014.

[27] M. Nilashi, S. Asadi, R. Ali, S. Samad, and O. Ibrahim, "Intelligent Recommender Systems in the COVID-19 Outbreak: The Case of Wearable Healthcare Devices," J. Soft Comput. Decis. Support Syst., vol. 7, no. 4, pp. 8-12, 2020.

[28] M. S. Rahman, N. C. Peeri, N. Shrestha, R. Zaki, U. Haque, and S. H. A. Hamid, "Defending against the Novel Coronavirus (COVID-19) outbreak: How can the Internet of Things (IoT) help to save the world?," Heal. Policy Technol., 2020, doi: 10.1016/j.hlpt.2020.04.005.

[29] A. K. Tripathy, A. G. Mohapatra, S. P. Mohanty, E. Kougianos, A. M. Joshi, and G. Das, "EasyBand: A Wearable for Safety-Aware Mobility during Pandemic Outbreak," in IEEE Consumer Electronics Magazine, pp. 1-5, 2020, doi: 10.1109/MCE.2020.2992034.

[30] R. P. Singh, M. Javaid, A. Haleem, and R. Suman, "Internet of things (IoT) applications to fight against COVID-19 pandemic," Diabetes Metab. Syndr. Clin. Res. Rev., vol. 14, no. 4, pp. 521-524, 2020, doi: 10.1016/j.dsx.2020.04.041.

[31] S. A. Fatima, N. Hussain, A. Balouch, I. Rustam, M. Saleem, and M. Asif, "IoT enabled Smart Monitoring of Coronavirus empowered with Fuzzy Inference System," Int. J. Adv. Res. Ideas Innov. Technol., vol. 6, no. 1, pp. 188-194, 2020, https://www.techscience.com/cmc/v65n3/40189.

[32] M. N. Mohammed, H. Syamsudin, S. Al-Zubaidi, A. K. Sairah, R. Ramli, and E. Yusuf, "Novel COVID-19 detection and diagnosis system using iot based smart helmet," Int. J. Psychosoc. Rehabil., vol. 24, no. 7, pp. 22962303, 2020, doi: 10.37200/IJPR/V24I7/PR270221.

[33] B. Wang, Y. Sun, T. Q. Duong, L. D. Nguyen, and L. Hanzo, "Risk-Aware Identification of Highly Suspected COVID-19 Cases in Social IoT: A Joint Graph Theory and Reinforcement Learning Approach," IEEE Access, vol. 8, pp. 115655-115661, 2020, doi: 10.1109/ACCESS.2020.3003750.

[34] G. Vasantharao and S. Arifunneesa, "Temperature Detection and Automatic Sanitization and Disinfection TunnelCOVID 19,” Int. J. Anal. Exp. modal Anal., vol. XII, no. VI, pp. 1175-1181, 2020.

[35] M. N. Mohammed, N. A. Hazairin, S. Al-Zubaidi, A. K. Sairah, S. Mustapha, and E. Yusuf, "Toward a novel design for Coronavirus detection and diagnosis system using iot based drone technology," Int. J. Psychosoc. Rehabil., vol. 24, no. 7, pp. 2287-2295, 2020, doi: 10.37200/IJPR/V24I7/PR270220.

[36] H. Ben Hassen, N. Ayari, and B. Hamdi, "A home hospitalization system based on the Internet of things, Fog computing and cloud computing," Informatics Med. Unlocked, vol. 20, p. 100368, 2020.

[37] L. Garg, E. Chukwu, N. Nasser, C. Chakraborty, and G. Garg, "Anonymity Preserving IoT-Based COVID-19 and Other Infectious Disease Contact Tracing Model," IEEE Access, vol. 8, pp. 159402-159414, 2020, doi: 10.1109/ACCESS.2020.3020513.

[38] M. Javaid, A. Haleem, R. Vaishya, S. Bahl, R. Suman, and A. Vaish, "Industry 4.0 technologies and their applications in fighting COVID-19 pandemic,” Diabetes Metab. Syndr. Clin. Res. Rev., vol. 14, no. 4, pp. 419-422, 2020, doi: 10.1016/j.dsx.2020.04.032.

[39] Z. Allam and D. S. Jones, "On the Coronavirus (COVID-19) Outbreak and the Smart City Network: Universal Data Sharing Standards Coupled with Artificial Intelligence (AI) to Benefit Urban Health Monitoring and Management," Healthcare, vol. 8, no. 1, p. 46, 2020, doi.org/10.3390/healthcare8010046.

[40] C. Dewey, S. Hingle, E. Goelz, and M. Linzer, "Supporting Clinicians During the COVID-19 Pandemic," in Annals of Internal Medicine, 2020.

[41] R. Vaishya, M. Javaid, I. H. Khan, and A. Haleem, "Artificial Intelligence (AI) applications for COVID-19 pandemic," Diabetes Metab. Syndr. Clin. Res. Rev., vol. 14, no. 4, pp. 337-339, 2020, doi.org/10.1016/j.dsx.2020.04.012. 